\title{
MULTI-INLET MIGRATION MODELING FOR NAVIGATION CHANNEL MANAGEMENT IN TABUSINTAC BAY, EASTERN CANADA
}

\author{
Vincent Leys ${ }^{1}$ and Moritz Lehmann ${ }^{2}$
}

\begin{abstract}
In New Brunswick, Atlantic Canada, Tabusintac Bay's multiple tidal inlets meander through narrow barrier islands and are prone to large storm-induced shifts, making navigation hazardous. A multi-evidence assessment comprised of air-photo analysis, field observations and modeling was undertaken to understand the system and recommend sustainable dredging strategies and/or engineering alternatives. The modeling relied on a combination of simple analytical methods for tidal inlet stability, and complex morphological modeling to project the evolution of the nearshore bathymetry. The study recommended reassigning dredging efforts to a new inlet projected to grow and have better stability. Observations two years after the initial modeling effort indicate that the morphological evolution is consistent with the simulation results, and allowed lowered maintenance dredging requirements. This study illustrates how such a multi-evidence assessment of complex coastal dynamics can concretely guide efforts to reduce maintenance dredging and improve safety at sea.
\end{abstract}

Keywords: dredging; tidal inlets; morphological modeling

\section{INTRODUCTION}

The shoreline of northeastern New Brunswick on the Gulf of St. Lawrence, Atlantic Canada, consists of a $14 \mathrm{~km}$ long system of barrier beaches fronting drowned river bays flushed by tides through sandy inlets (Figure 1). At Tabusintac Bay, the narrow barrier islands are prone to breaches from northeasterly storm waves, and tidal inlets tend to migrate southward with the longshore sediment transport.

Before 2010, the only inlet large enough to be used for navigation was located approximately 6 $\mathrm{km}$ away from the fishing harbour to the South (inlet \#5 on the map, see Figure 1). A storm in December 2010 cut open a new inlet closer to the harbour (inlet \#3), which became the fishermen's shortest and preferred route at that time. However, the new inlet's shifting shoals represented a serious navigational hazard. To compound the issue, due to southerly longshore drift, the new navigation route through this inlet had become almost parallel to wave crests, resulting in destabilizing beam-on waves impacting vessels. Initial dredging efforts on the new inlet \#3 were hampered by strong sediment transport rapidly infilling the dredged channel.

Navigation safety and dredging requirements were the key issues from the natural setting of the site and its usage. This study was commissioned to examine alternative inlet dredging strategies, and to evaluate potential engineering alternatives such as jetties. The modeling relied on a combination of simple analytical methods for tidal inlet stability, and complex morphological modeling to project the evolution of the nearshore bathymetry.

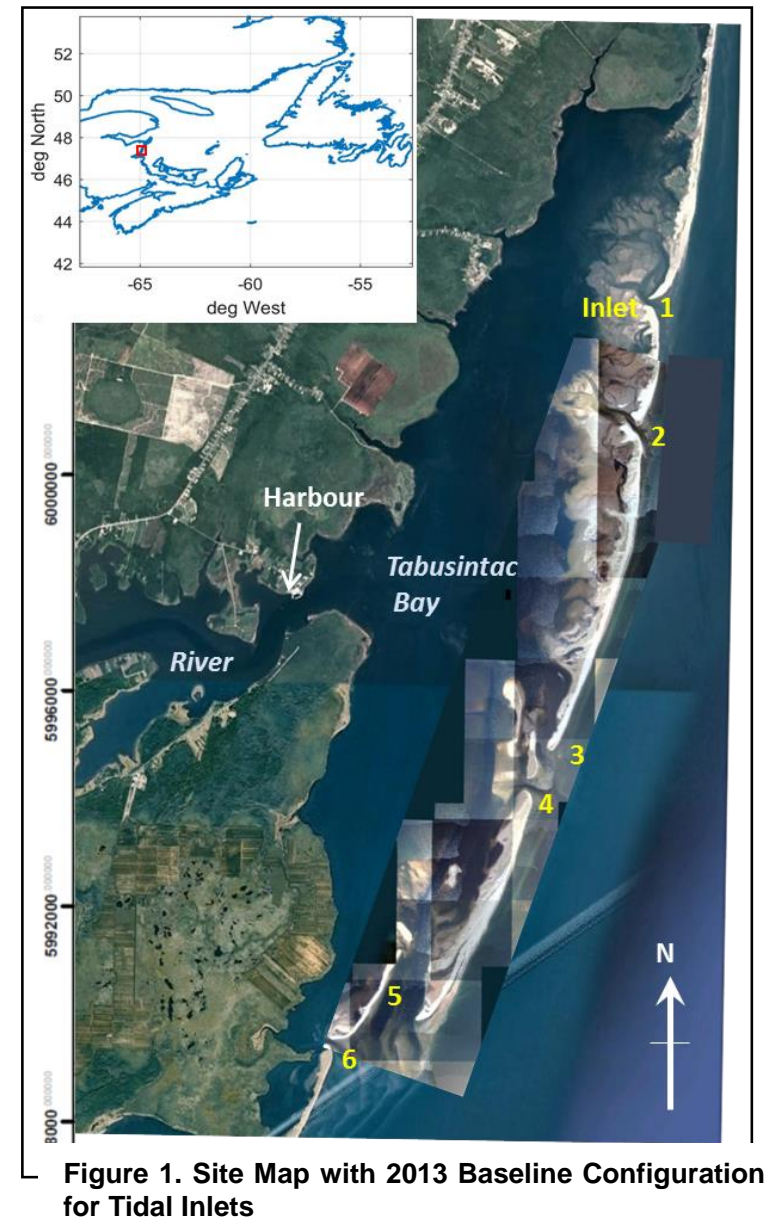

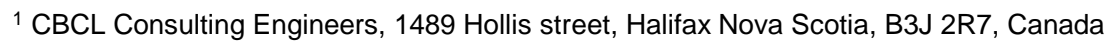

2 University of Waikato, Hillcrest, Hamilton 3216, New Zealand 


\section{TYPICAL ISSUES AT MULTI-INLET BAYS}

Natural tidal inlets through barrier beaches and islands are subject to frequent change. Unless restricted by engineered structures or by naturally occurring obstacles, they commonly migrate alongshore in a downdrift direction. Barrier systems with multiple inlets are particularly unstable, because changes to one inlet, such as shoaling or deepening, alter the hydrodynamics of the entire system and affect the morphology of the other inlets (FitzGerald, 1993). The evolution of inlet creation and closure is often cyclical over long periods of time, i.e., decades to centuries (Weidman \& Ebert, 1993).

Quantifying these processes is critical for informed dredging practices at navigation channels. The instability of tidal inlets can create hazards to navigation, changes in local wave impact, and effects on water quality and shellfishing activities. To mitigate some of these impacts, many tidal inlets around the world have been stabilized by jetties (i.e., shore-perpendicular training structures) or other rigid structures. While these alterations may have alleviated the primary concern, in many cases additional problems occurred that necessitated continuous maintenance or further engineered alterations (FitzGerald, 1993). A common effect of the interruption of natural drift of sediment is the updrift accretion of sediment which may require either dredging to prevent sand to spill-over into the navigational channel, or periodic extension of the jetty. Downdrift of the jetty, the interruption of sediment transport may cause erosion to the point of breaching of the barrier beach during storm events. In some cases jetties were built into the direction of oncoming waves causing treacherous navigation over shoals forming from landward sand transport. Any engineering activities should also be careful not to reduce the existing tidal prism, i.e. the volume of water exchanged during one tidal cycle, which is key for sustained flushing of the bay and channels.

\section{HISTORICAL EVOLUTION 1945-2015}

In 1945 the principal inlet used by fishing vessels from Tabusintac Bay was located due East of the harbour (Figure 2). During the 1950's, 1960's and 1970's the principal inlet continued migrating south, with two channels seen on the 1974 photos. This southward migration occurred either continuously or through closure and breaching. This was a period of continued change. Historical records indicate that dredging attempts were conducted through the barrier island due East of the harbour in the 1960's and 1970's, but the southward longshore transport rapidly filled in the dredged channels (Reinson et al 1980).

The late 1970's until year 2010 were a period of relative stability. Despite its annual shifts, the main inlet to the South (\#5) had remained the preferred route for fishermen due to its strong tidal currents maintaining a relatively deep channel. In 2010, the barrier island breached to form a new inlet due East of the harbour, close to the 1945 inlet location. This location significantly reduced navigation times out of the bay, but the channel was shallow and continuously migrating to the south. In the spring of 2013 the new inlet was split into two channels (\#3 and \#4) around a flood-delta island.

The study, completed in 2014, indicated that inlet \#3 would likely close and \#4 would recapture the tidal prism. The recommendations was therefore to refocusing dredging efforts on inlet \#4. The 2015 photo shows the natural closure of \#3.

The following sections of this paper summarize the 2014 stability assessment based on multiple methods that led to the validated recommendation. 


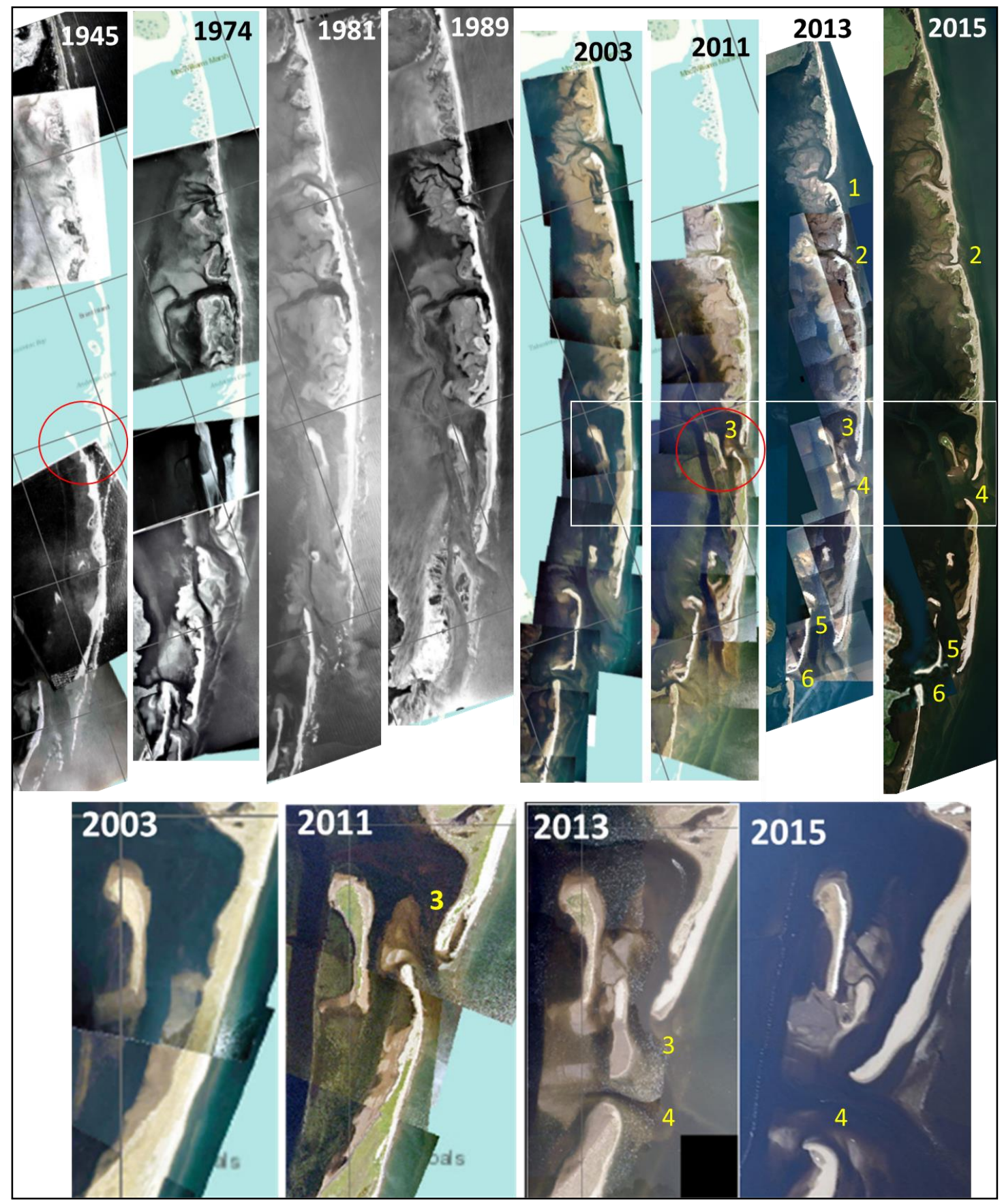

Figure 2. Historical Evolution of Tabusintac Inlets. The baseline year for the study was 2013, with six inlets numbered 1 to 6 . The system shows a cyclical behavior, with inlet \#3 breaching through the dune in 1945 and 2010 (red circle), then steadily migrating south. A close-up on inlets \#3 and \#4 (bottom) reveals the temporary nature of inlet \#3 until inlet \#4 recaptured the tidal flow. Southward migration rates for southern inlets \#3 and \#5 was estimated at 100 to $200 \mathrm{~m} /$ year. Migration rates for northern inlets \#1 and \#2 is approximately half that of southern inlets. The dunes do not show significant migration to the west, which suggests there is limited sand to keep up with sea level rise. As a result, the barrier beach system will be increasingly vulnerable to breaches during storm surges. 


\section{INLET STABILITY ANALYSES ON 2013 BASELINE}

Following bathymetric surveys at each inlet, a DHI MIKE21 model of the system was developed and calibrated to tide gauge observations recorded in the summer of 2013. The local tides are mixed diurnal to semi-diurnal in character. The measured tidal passage to the bay through the inlets ranged from 55 to $65 \%$ depending on the tidal range. The achieved error margin in tidal range from the hydrodynamic model was a satisfactory $\pm 5 \%$. As a first step, the hydrodynamic model was used to determine tidal prism through the inlets. Each inlet's tidal prism was computed by integrating the discharge over each ebb or flood spring tide. This volume represents each inlet's contribution to the tidal prism of Tabusintac Bay. The total tidal prism through all inlets for the whole bay was estimated at 31 million $\mathrm{m}^{3}$

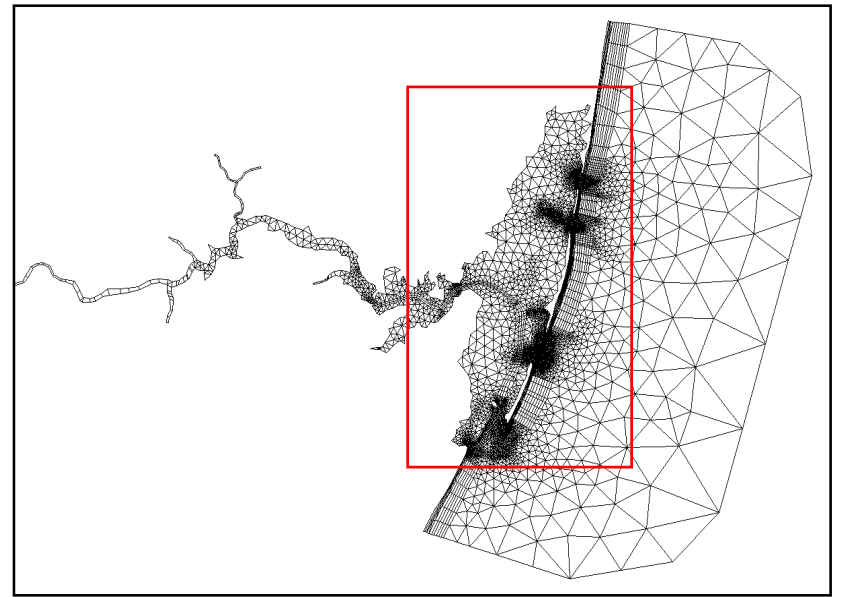

Figure 3. Hydrodynamic model domain

Inlet stability can refer to either the cross-sectional area of the channel across the inlet throat, or to the inlet location. Since the tidal prism must enter and exit through the relatively constricted inlet, flow increases and sediment is scoured until the inlet erodes to a stable channel cross sectional area. A natural channel is only stable when it is both large enough to allow full tidal passage yet small enough so constricted tidal currents flush the excess sand out. The cross sectional areas of the Tabusintac inlets were deemed to be in equilibrium, based on empirical relationships by Jarrett (1976) between tidal prism and inlet throat cross sectional area (Figure 4).

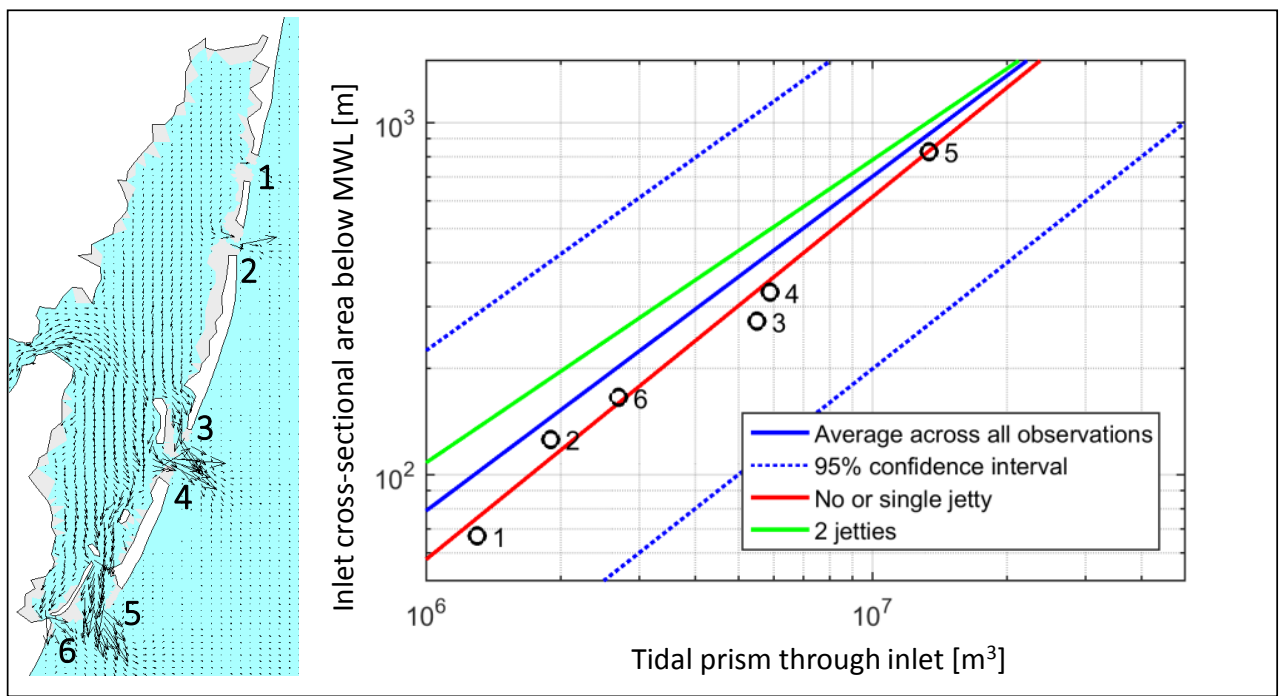

Figure 4. Empirical Equilibrium Inlet Cross Sectional Area vs. Tidal Prism. The lines are from best-fit relationships derived by Jarrett (1976) based on observed tidal inlets worldwide. The individual data points are modeled Tabusintac inlets 1 to 6 using year 2013 baseline bathymetry. 
In terms of inlet stability, the key question is whether the inlet would tend to close or scour itself back to equilibrium after sudden storm-induced deposition events reduce the cross section. Small entrance channels that limit tidal passage are dominated by friction and their equilibrium is unstable. If a storm reduces the cross-section, friction increases, tidal passage decreases and the maximum velocity decreases, leading to more infilling and ultimate closure of the inlet and relocation of the channel to a more hydraulically efficient location. When the cross section is wide enough for most of the tide to go through, the influence of friction is much reduced. Storm-induced sedimentation would then increase maximum velocities, helping the channel scour itself back to stable equilibrium. The analytical assessment method we used was summarized by Dean and Dalrymple (2002), and is referred to as the Escoffier closure curves. Escoffier's method was applied to the Tabusintac inlets. The results indicate inlets \#1 and \#3 were unstable in 2013 and at risk of closing during a storm (Figure 5). Other inlets appeared stable, i.e., not at risk of closure, although their location itself would be unstable due to the strong longshore drift.

The post-study evolution since 2013 validated these analyses, as seen on the air photos. The inlets \#1 and \#3 assessed as unstable in 2013 have closed. This illustrates that relatively simple analytical methods based on accurate measurements can be effective for predicting morphological change, and should be applied as a first step before more complex morphological modeling as presented next.

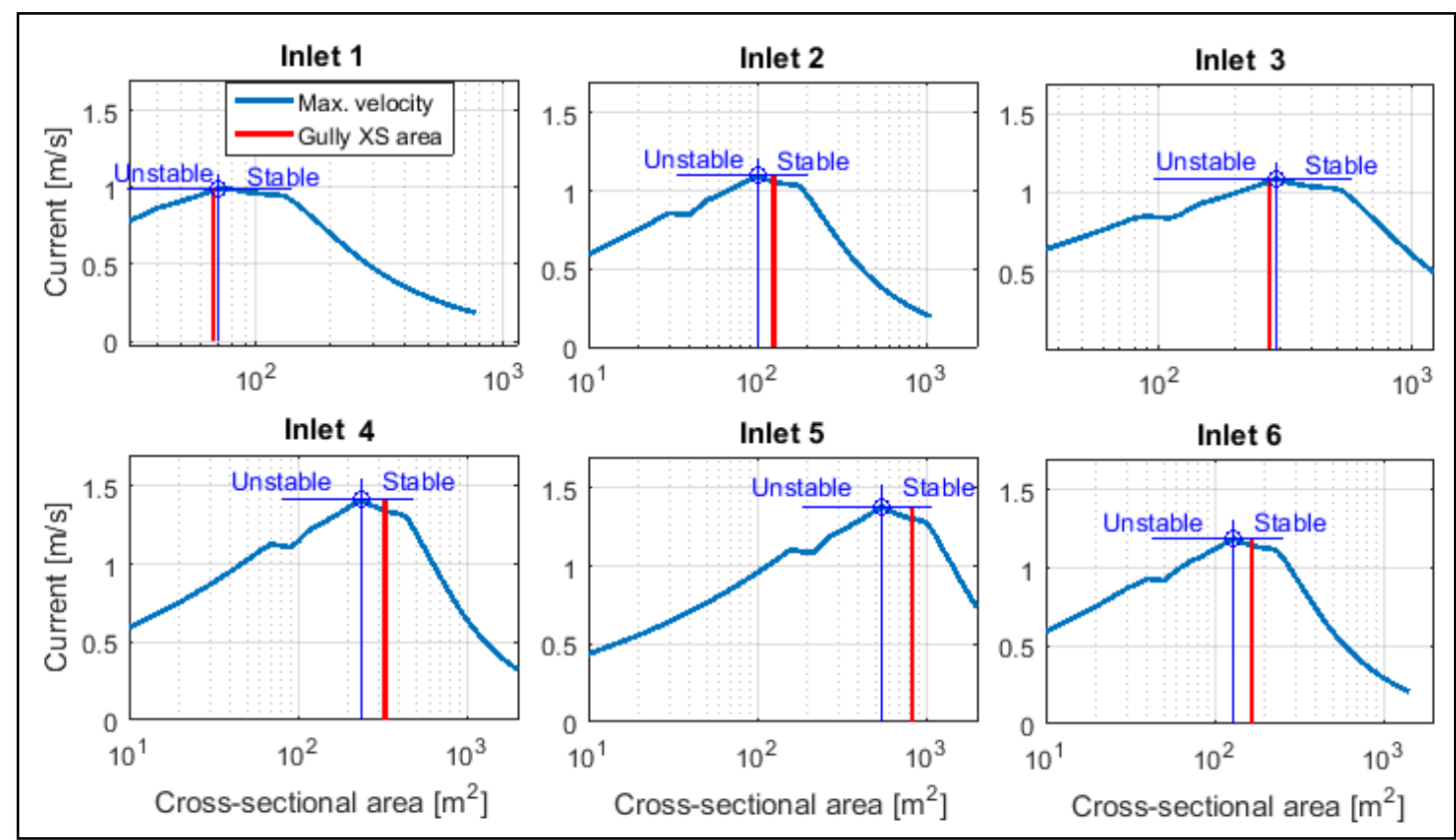

Figure 5. Inlet Closure Curves for 2013 Bathymetry. The analysis serves to determine whether the inlet crosssections were in a state of stable equilibrium (i.e. self-scouring) or unstable equilibrium (i.e. at risk of closure). Based on Escoffier's method as summarized by Dean and Dalrymple (2002) 


\section{WAVES AND LONGSHORE SEDIMENT TRANSPORT}

The spectral wave and sediment transport modules of MIKE21 were coupled to the calibrated hydrodynamic model. An example of modeled wave heights for the 10-year return storm from the Eastnortheast direction is shown on Figure 6. Breaking waves generate a strong southward longshore current along the barrier beaches. The current and associated sediment transport intensifies along the southern half of the barrier island system that is at a sharper angle to the incident wave crests.

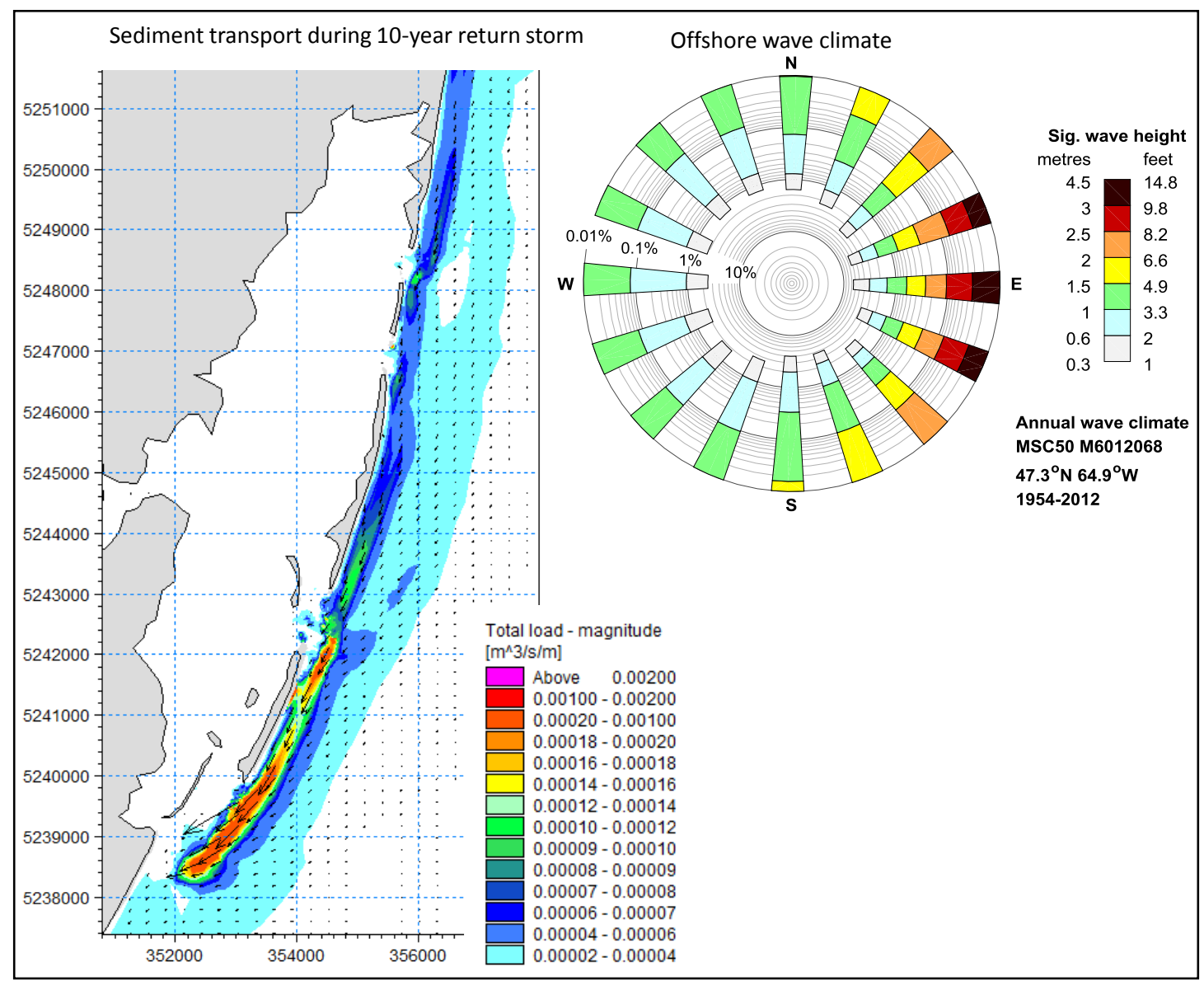

Figure 6. Modeled Prevailing Sediment Transport Pattern.

As also verified by bulk longshore transport equations (CERC 1984 and Kamphuis 1991 formulas, as described in Kamphuis 2000), the net southerly transport is approximately twice greater along shorelines oriented NNE-SSW than along shorelines oriented North-South. This is consistent with inlet migration rates estimated from air photos, which are twice as fast for south inlets as for north inlets. The largest net longshore transport values for the southern inlets was estimated at approximately 140,000 $\mathrm{m}^{3} /$ year. Historical trends indicate that the occurrence of higher wave activity has increased steadily over the last decades due to the decrease in winter ice cover. We estimate that gross longshore sediment transport rates have likely doubled in the last 50 years. The trend is set to accelerate, as scientists indicate that the Gulf may be free of ice by year 2045 (McCulloch et al. 2002, Forbes et al. 2004).

Finally, for a tidal inlet to remain both naturally self-scouring and laterally stable along its barrier beach, both a large tidal exchange and low net longshore transport are required. Unfortunately, Tabusintac Bay does not offer such a combination, neither at its north nor at its south section. While the net longshore transport along its north section (year 2013 inlets \#1 and \#2) is relatively lower, the proportion of the total tidal prism captured there is limited due to shallow depths and the absence of major channels. In contrast, the south section of the bay (year 2013 inlets \#3, \#4 and \#5) has more tidal flushing, but strong southward longshore transport. 


\section{MORPHOLOGICAL MODEL}

A morphological model was developed to examine the potential evolution of the bathymetry under the combined action of waves and tidal currents, with dynamic feedback from the bed level changes into the waves and hydrodynamic modules. The objective was to evaluate alternatives to current dredging practices. Morphological modeling is still a research-oriented field where the accuracy of model predictions is limited by a number of factors, including:

- Model approximations in the representation of complex processes, dynamics and interactions. In the present case, breaches through the islands were not modeled;

- Limited availability of detailed topographic and geotechnical data along the entire length of the beach system (this limitation can now be overcome with topo-bathymetric LiDAR);

- Uncertainty in future oceanographic conditions such as storm frequency and direction; and

- Computational limitations, which require the use of artificial speedup factors that decrease the confidence in model predictions for the long-term.

The results presented here show the evolution of the nearshore bed level to the high water mark and include the bathymetric changes along the perimeter of the barrier islands. Therefore, the bed level changes are predicted with confidence in the short to medium-term until an unpredictable event, such as a breach or extreme storm surge may occur and alter the evolution from that predicted.

A multi-year simulation was prepared based on speedup techniques as recommended by Jones et al, 2007. These included a morphological speedup factor of 4 and constant storm wave boundary conditions using the 10-year return extreme values. The simulation provided likely outcomes from the 2013 baseline over the following years (Figure 7). The model indicated growth of secondary inlet \#4 to the South, and gradual closure of inlet \#3 used for navigation in 2013. It was therefore recommended to reassign dredging efforts to inlet \#4.

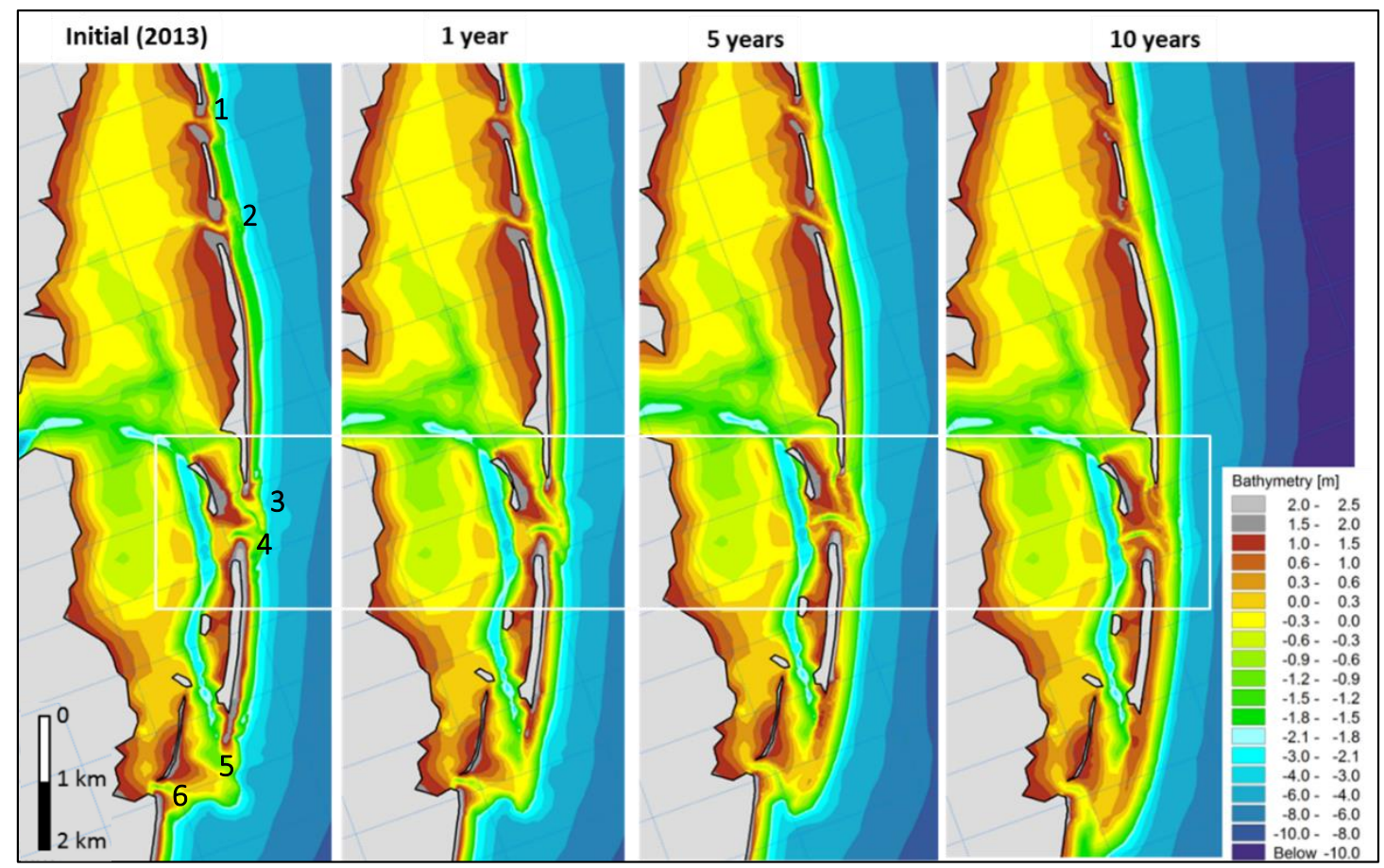

Figure 7. Modeled post-2013 evolution of the nearshore bathymetry (showing air photo area from Figure 2 inside white boundaries). The simulation indicated closure of inlet \#3 within less than 5 years with inlet \#4 recapturing its tidal prism, which proved accurate. The simulation does not include maintenance dredging, or sudden breaches through the barrier islands. 


\section{CONSIDERATIONS ON NEW JETTIES}

The morphological model was also used to estimate maintenance dredging requirements at inlets trained with new jetties. It was found that some amount of maintenance dredging would always be required regardless of the chosen inlet for the new jetties. This is not surprising for this site, because coastal engineering works at tidal inlets typically attempt to balance conflicting requirements (Kraus 2008):

- Reduce sediment inputs to minimize dredging, while assuring sediment bypassing continues to feed adjacent beaches to minimize downdrift erosion; and

- Increase the currents to reduce channel infilling, but keep the currents low enough for navigation safety.

The morphologic consequence of jetties includes updrift accretion and downdrift erosion, which may be mitigated (but not eliminated) by downdrift placement of dredge material. This effect is stronger in areas of higher longshore transport, i.e. it will be greater at the south inlets than north inlets. While jetties will encourage stability at a selected inlet, overtopping and potential breach development elsewhere along the islands will continue and with increasing frequency due to sea level rise. Importantly, downdrift erosion to the south of the structures will increase the likelihood of breaches. At Tabusintac the local elevation difference between a 1 -year return and a 50-year return storm surge is only $0.5 \mathrm{~m}$. Therefore, sea level rise will greatly increase the frequency of potentially breach-inducing storm surges. If a new breach develops between the trained inlet and an existing natural inlet, tidal flushing in the trained inlet will decrease, causing sedimentation. This represents the most important risk to the options involving fixed jetties.

\section{YEAR 2014 RECOMMENDATIONS}

Key findings of the modeling study were as follows, based on life-cycle cost estimates for the various options and on the understanding of the coastal processes:

- There is no option available that does not require regular (likely annual) maintenance dredging;

- Sea level rise and storm surges will pose increasing challenges to the area, with continued inlet migration and breaches. From the perspective of sustainable long-term adaptation, fixed engineered structures at one inlet are not advisable because of the barrier island system's increasing vulnerability to breaches. Jetties would trigger dune erosion on the downdrift side to the south, increasing the likelihood of breaches. Future breaches may split the bay's tidal prism across more shallow inlets, increasing sedimentation at the jettied inlet.

It was therefore recommended to enlarge inlet \#4 through dredging, and dispose of dredged material on south side downdrift. This year-to-year adaptive dredging approach is meant to work with the channel's expected southward migration and the strategy must be flexible in case the channel's dimensions change while another inlet re-opens elsewhere.

\section{POST-MODEL OUTCOMES AND RECENT DEVELOPMENTS}

Observations since the initial modeling effort indicate that the multi-inlet migration is consistent with the simulation results. The 2011-2013 navigation channel at inlet \#3 closed and the new south channel at inlet \#4 widened. Widening of the back channel of inlet \#4 was further accelerated in 2014 and 2015 through initial dredging. In 2016 inlet \#4 had stabilized to a large enough size that no maintenance dredging was required. Ongoing topo-bathymetric and air photo monitoring are continuing to improve our understanding of the system, so dredging can be re-assigned on an as-needed basis. This study illustrates how a multi-evidence assessment comprised of air-photo analysis, field observations and modeling can produce useful predictions of complex coastal dynamics concretely guide efforts to reduce maintenance dredging and improve safety at sea.

\section{ACKNOWLEDGMENTS}

The author thanks Public Works and Government Services Canada and the Small Craft Harbours Branch of the Department of Fisheries and Oceans for providing funding for the study. Valuable field work assistance from the Harbour Authority of McEachern's Point is also gratefully acknowledged. 


\section{REFERENCES}

Dean, R.G., and Dalrymple, R.A. 2002. Coastal processes with engineering applications. Cambridge U. Press, 475p

FitzGerald, D. M., Origin and Stability of Tidal Inlets in Massachusetts in Formation and evolution of multiple tidal inlets. D. G. Aubrey and S. Giese, eds., Washington DC, 1993.

Forbes D.L., Parkes G.S., Manson G.K., and Ketch L.A., 2004. Storms and Shoreline Retreat in the Southern Gulf of St. Lawrence. Marine Geology 210 (pp 169- 204).

Jarrett, J.T. (1976). Tidal Prism-Inlet Area Relationships. GITI Report 3, U.S. Army Waterways Experiment Station, Vicksburg, MS.

Jones O.P., Petersen O.S., Kofoed-Hansen H. 2007. Modelling of complex coastal environments: Some considerations for best practice. Coastal Engineering 54 (2007) 717-733, Elseveier B.V.

Kamphuis J. W. 2000. Introduction to Coastal Engineering and Management. World Scientific. ISBN 981-02-3830-4

Kraus N.C, 2008. Engineering of Tidal Inlets and Morphologic Consequences, USACE Research and Development Centre. In: Kim Y.C. Handbook of Coastal and Ocean Engineering. World Scientific ISBN-10 981-281-929-0.

McCulloch M. M., Forbes D.R., Shaw R.W. and A041 Scientific Team. 2002. Coastal Impacts of Climate Change and Sea Level Rise on Prince Edward Island. Geological Survey of Canada. Open File 4261.

Pacheco A., Ferreira O., Williams J.J., Garel E., Vila-Concejo A., Dias J.A. 2010. Hydrodynamics and equilibrium of a multiple-inlet system. Marine Geology 274 (20100 32-42.

Reinson G.E. 1980. Variations in Tidal Inlet Morphology and Stability, Northeast New Brunswick. In: The Coastline of Canada, S.B. McCann, editor; Geological Survey of Canada, Paper 80-10, p. 2339, 1980.

Reinson G.E., Frobel D. 1980. Effects of Dredging Activities on Shoreline Morphology and Stability, Northeast New Brunswick. Atlantic Geoscience Centre, Geological Survey of Canada, Bedford Institute of Oceanography, Dartmouth Nova Scotia.

Swail V.R, Cardone V.J., Ferguson M., Gummer D.J., Harris E.L., Orelup E.A. and Cox A.T. 2006. The MSC50 Wind and Wave Reanalysis. 9th International Workshop On Wave Hindcasting and Forecasting September 25-29, 2006 Victoria, B.C. Canada.

Weidman, C. R. and J. R. Ebert, Cyclic Spit Morphology in a Developing Inlet System in Formation and evolution of multiple tidal inlets. D. G. Aubrey and S. Giese, eds., Washington DC, 1993. 